\title{
Uporabnost izbranih invazivnih tujerodnih rastlin pri zatiranju škodljivih organizmov gojenih rastlin
}

\author{
Žiga LAZNIK ${ }^{1}$, Tanja BOHINC ${ }^{2}$, Stanislav TRDAN ${ }^{3}$
}

Received January 18, 2018; accepted July 02, 2018.

Delo je prispelo 18. januarja 2018, sprejeto 02. julija 2018.

\section{IZVLEČEK}

Invazivne tujerodne rastline $\mathrm{s}$ hitrim razširjanjem povzročajo nemalo težav ne le domorodnim sortam rastlin, ker jih spodrivajo, temveč tudi ljudem, saj so pogosto vzrok za številne zdravstvene težave, kot so alergije, pripomorejo pa tudi k večji gospodarski škodi. Varstvo rastlin je dejavnost, ki na podlagi ustreznih znanstvenih dognanj $\mathrm{z}$ različnimi metodami in na gospodaren način varuje gojene rastline pred škodljivimi organizmi. Pri nas in drugod po svetu je zaradi cene in drugih prednosti najbolj razširjena uporaba fitofarmacevtskih sredstev (FFS) v varstvu rastlin pred škodljivimi organizmi. Zaradi negativnih vplivov na okolje, njihovega neciljnega delovanja, pojava rezistence škodljivih organizmov na FFS in vse strožje okoljske politike raziskovalci iščejo nove, okoljsko bolj sprejemljive načine varstva rastlin pred škodljivimi organizmi. Eden od tovrstnih ukrepov je tudi preučevanje rastlinskih izvlečkov pri zatiranju gospodarsko pomembnih škodljivih organizmov. V preglednem članku smo se osredotočili na pregled literature vezane na uporabnost rastlinskih izvlečkov izbranih tujerodnih rastlinskih vrst $\mathrm{v}$ varstvu rastlin; japonskega dresnika (Fallopia japonica [Houtt.] Ronse Decr.), češkega dresnika (Fallopia x bohemica [Chrtek \& Chrtková] Bailey), velikega pajesena (Ailanthus altissima [Mill.] Swingle), kanadske zlate rozge (Solidago canadensis L.), orjaške zlate rozge (Solidago gigantea Aiton), octovca (Rhus typhina L.), navadne amorfe (Amorpha fruticosa L.) in smrdljivo ditrihovko (Dittrichia graveolans [L.] Greuter), ki jih preučujemo v sklopu projekta ApPLAuSE.

Ključne besede: invazivne rastlinske vrste; Fallopia japonica; Fallopia x bohemica; Ailanthus altissima; Solidago canadensis; Solidago gigantea; Rhus typhina; Amorpha fruticosa; rastlinski izvlečki; varstvo rastlin

\section{ABSTRACT \\ APPLICABILITY OF INVASIVE ALIEN PLANTS IN CONTROLLING HARMFUL ORGANISMS OF CULTIVATED PLANTS}

With a rapid growth invasive alien plants cause a lot of problems not only to indigenous varieties of plants, but also for people, as they are often the cause of many health problems, such as allergies, and they also contribute to greater economic loss. Plant protection is an activity which, on the basis of appropriate scientific knowledge by means of various methods and an economical manner, protects cultivated plants from harmful organisms. In Slovenia, as well as worldwide, the use of pesticides in plant protection programmes is the most widespread method due to price and other benefits. Researchers are looking for new, environmentally more acceptable ways of protecting plants against harmful organisms due to adverse environmental effects of pesticides, their non-target activity, the occurence of resistance to pesticides, and increasingly stringent environmental policies. One such measure is also the study of plant extracts in the suppresing of economically important harmful organisms. In a review article, we focused on the literature review of the usefeulness of plant extracts of several invasive alien plant species in plant protection: knotweeds (Fallopia japonica [Houtt.] Ronse Decr), F. $x$ bohemica (Chrtek \& Chrtková) Bailey), goldenrods (Solidago canadensis L., S. gigantea Aiton), stag's-horn sumac (Rhus typhina L.), tree of heaven (Ailanthus altissima [Mill.] Swingle), false indigo (Amorpha fruticosa L.) and stinkwort (Dittrichia graveolens [L.] Greuter), which we are studying within the project ApPLAuSE.

Key words: invasive alien plant species; Fallopia japonica; Fallopia x bohemica; Ailanthus altissima; Solidago canadensis; Solidago gigantea; Rhus typhina; Amorpha fruticosa; plant protection

\footnotetext{
1 doc. dr., univ. dipl. inž. agr., Univerza v Ljubljani , Biotehniška fakulteta, Oddelek za agronomijo, Jamnikarjeva 101, SI-1000 Ljubljana, email: ziga.laznik@bf.uni-lj.si

2 dr., prav tam

3 prof. dr., prav tam
} 


\section{UVOD}

Tujerodna rastlinska vrsta je tista, ki se na nekem območju brez posredovanja človeka ne bi mogla pojaviti. Ko te rastline na nekem novem območju vzpostavijo svoje nove populacije, se začnejo širiti v skladu s svojimi načini širjenja na primarnih območjih uspevanja (Jogan in sod., 2012). Poznamo arheofite. To so tujerodne rastlinske vrste, katerih pojav $\mathrm{v}$ naših krajih je povezan $\mathrm{z}$ delovanjem človeka in so se pojavile po koncu pleistocena. Omenjene vrste so $\mathrm{k}$ nam prihajale iz območja jugovzhodne Evrope in iz Bližnjega Vzhoda. Poznamo tudi t.i. neofite. Gre za rastlinske vrste, ki so se $\mathrm{v}$ njim tujih krajih $\mathrm{s}$ pomočjo človeka pojavile $\mathrm{v}$ zadnjih 500 letih (Jogan in sod., 2012).

Večina tujerodnih rastlinskih vrst $\mathrm{v}$ novem okolju ni invazivnih. O invazivni vrsti govorimo tedaj, ko se neka tuja vrsta nezadržno širi $\mathrm{v}$ predelih $\mathrm{s}$ podobnim podnebjem. Gre za neke vrste »invazijski potencial«, ki ga te rastline razvijejo, ko se pojavijo v konkurenčno šibkejšem tujem okolju (Jogan in sod., 2012). Jogan in sod. (2012) navajajo, da se pri nas vsaj občasno v naravi pojavlja okoli 750 tujerodnih vrst, od katerih se jih je 330 že udomačilo.

Stroški zatiranja invazivnih vrst in odprave škode zaradi njihovega delovanja so $\mathrm{v}$ letu $2012 \mathrm{v}$ EU znašali med 10,6 do 14 milijard evrov (Sladonja in sod., 2015). Od leta 1992 je bilo v EU porabljenih več kot 38 milijonov evrov za 180 projektov, tako $\mathrm{v}$ mreži zavarovanih območij Natura 2000 kot zunaj nje (Shaw in sod., 2009). V ZDA ocenjujejo, da na leto porabijo približno 80 milijard evrov za zatiranje invazivnih vrst (Blackburn in sod., 2004). V popisu invazivnih vrst DAISIE je bilo v Evropi ugotovljenih 10.822 tujerodnih vrst. Vse med njimi niso invazivne, a se ocenjuje, da jih približno od 10 do $15 \%$ lahko ogroža evropsko biotsko raznovrstnost (Sladonja in sod., 2015).

Varstvo rastlin (fitomedicina) je dejavnost, ki na podlagi ustreznih znanstvenih dognanj z različnimi metodami in na gospodaren način varuje gojene rastline pred škodljivimi organizmi za ohranitev in povečanje pridelka ter njihove kakovosti. V varstvu rastlin uporabljamo različne metode: agrotehnične, fizikalne, kemične, biotične in biotehnične (Milevoj, 2011). Pri nas in drugod po svetu je zaradi cene in drugih prednosti najbolj razširjena uporaba fitofarmacevtskih sredstev (FFS) v varstvu rastlin pred škodljivimi organizmi. Zaradi negativnih vplivov na okolje (ostanki FFS v rastlinah in $\mathrm{v}$ tleh), njihovega neciljnega delovanja, pojava rezistence škodljivih organizmov na FFS in vse strožje okoljske politike (umik številnih FFS iz trgovskih polic) raziskovalci iščejo nove, okoljsko bolj sprejemljive načine varstva rastlin pred škodljivimi organizmi. Eden od tovrstnih ukrepov je tudi preučevanje rastlinskih izvlečkov pri zatiranju gospodarsko pomembnih škodljivih organizmov (Pavela in sod., 2008).

$\mathrm{V}$ preglednem članku se osredotočamo na pregled literature vezane na uporabnost rastlinskih izvlečkov nekaterih tujerodnih rastlinskih vrst $\mathrm{v}$ varstvu rastlin; japonskega dresnika (Fallopia japonica [Houtt.] Ronse Decr.), češkega dresnika (Fallopia x bohemica [Chrtek \& Chrtková] Bailey), velikega pajesena (Ailanthus altissima [Mill.] Swingle), kanadske zlate rozge (Solidago canadensis L.), orjaške zlate rozge (Solidago gigantea Aiton), octovca (Rhus typhina L.), navadne amorfe (Amorpha fruticosa L.) in lepljive ditrihovke (Dittrichia viscosa [L.] Greuter), ki jih preučujemo v sklopu projekta ApPLAuSE.

\section{TUJERODNE RASTLINSKE VRSTE}

\subsection{Dresniki iz rodu Fallopia}

Znanstveniki so preučevali vpliv rastlinskih izvlečkov različnih vrst dresnikov pri zatiranju nekaterih gospodarsko pomembnih škodljivih organizmov. Možno uporabo listnih izvlečkov sahalinskega dresnika so kot prvi omenili Herger in sod. (1988), ko so preučevali učinkovitost izvlečkov različnih rastlinskih vrst pri zatiranju kumarne pepelovke (Erysiphe polyphaga Hamm.). V njihovi raziskavi se je širjenje te glivične bolezni najbolj ustavilo (med 60 in $80 \%$ zmanjšanje okužbe) ravno pri uporabi vodnega in alkoholnega izvlečka sahalinskega dresnika. V nadaljnjih raziskavah so rastlinski izvleček sahalinskega dresnika uporabili tudi drugi raziskovalci pri zatiranju nekaterih vrst pepelovk, ki so se pojavile na paradižniku, begoniji in jablani (Herger in Klingauf, 1990; Neuhaus in Pallut, 1992; KonstantinidouDoltsinis in Schmitt, 1998; Konstantinidou-Doltsinis in sod., 2006). Na podlagi uspešnih rezultatov so raziskovalci $\mathrm{v}$ povezavi $\mathrm{s}$ podjetjem $\mathrm{BASF}$ razvili proizvod Milsana ${ }^{\circ}$, katerega formulacija temelji na rastlinskem izvlečku sahalinskega dresnika. Proizvod je registriran kot sredstvo za dvig odpornosti rastlin in ga tržijo v Evropi, v obeh Amerikah, na Japonskem ter v Južnoafriški Republiki (Konstantinidou-Doltsinis in sod., 2006). Nekatere poznejše raziskave so pokazale, da lahko pripravek Milsana ${ }^{\circledR}$ sočasno uporabljamo z nekaterimi drugimi sredstvi za varstvo rastlin 
(Mycotal ${ }^{\circledR}$, a.s. Lecanicillium muscarium, ciljni organizem: tobakov ščitkar [Bemisia tabaci (Gennadius)]) in tako pri enkratnem nanosu uspešno zatiramo več škodljivih organizmov hkrati (Bardin in sod., 2008). Francoski raziskovalci omenjeno kombinacijo priporočajo pri zatiranju pepelovke in ščitkarja na paradižniku, gojenem $\mathrm{v}$ rastlinjaku. Za uspešno kombinacijo se je tudi pokazala sočasna uporaba pripravkov Milsana ${ }^{\circledR}$ ter Sporodex L (a.s. Pseudozyma flocculosa) pri zatiranju pepelovke Uncinula necator (Schwein.) Burrill (KonstantinidouDoltsinis in sod., 2007). Lalancette in sod. (2013) so v dvoletnem poskusu na prostem preizkušali učinkovitost devetih rastlinskih bioloških fungicidov pri zatiranju jablanove pepelovke (Podosphaera leucotricha [Ellis \& Everh.] E.S. Salmon) na breskvah (sorta 'Jerseyglo'). Rastlinski izvleček sahalinskega dresnika v omenjeni raziskavi ni signifikantno vplival na zmanjšanje okužbe $\mathrm{z}$ omenjeno glivično boleznijo na breskvah. Rastlinski izvleček sahalinskega dresnika je bil uporabljen pri zatiranju navadne pršice (Tetranychus urticae C. L. Koch) na kumarah, gojenih v rastlinjaku (Tomczyk, 2006). Razmnoževanje in širjenje pršice je bilo zmanjšano za $34 \%$. V laboratorijski raziskavi so raziskovalci preučevali vpliv metanolnega izvlečka sahalinskega, japonskega in češkega dresnika na razvoj gosenic vrste Spodoptera littoralis Boisduval (Lepidoptera: Noctuidae) (Pavela in sod., 2008). Rezultati njihove raziskave so pokazali, da rastlinski izvlečki niso vplivali na smrtnost gosenic, so se pa te manj hranile.

Znano je, da zastopanost japonskega dresnika vpliva na zmanjšano pestrost drugih rastlinskih vrst (Aguilera in sod., 2010; Moravcova in sod., 2011; Murrell in sod., 2011; Stoll in sod., 2012). Znanstveniki so v raziskavah potrdili, da korenike japonskega dresnika (Fallopia japonica) izločajo kemične spojine, ki delujejo alelopatsko (Vrchotová in Šerá, 2008; Tucker Serniak, 2016). Tucker Serniak (2016) je v raziskavi preučeval alelopatski vpliv kemičnih snovi resveratrol, emodin, polidatin ter epikatehin na rast sadik redkve (Raphanus sativus L.). Gre za kemične snovi, ki se nahajajo v koreninskih izvlečkih japonskega dresnika (Fan in sod., 2010). Rezultati raziskave so pokazali, da kemične snovi resveratrol, emodin in epikatehin vplivajo na slabši razvoj korenin redkve. Do podobnih ugotovitev so prišli tudi drugi raziskovalci (Vrchotová in Šerá, 2008; Murrell in sod., 2011), ki so potrdili alelopatski učinek rastlinskih izvlečkov, pridobljenih iz različnih rastlinskih delov japonskega, češkega in sahalinskega dresnika, na razvoj nekaterih vrst metuljnic in zeli.

\subsection{Rastlinske vrste iz rodu Dittrichia Greuter}

Tako tuji kot tudi domači raziskovalci ugotavljajo negativen učinek rastlinskih izločkov ditrihovk na kalitev in razvoj korenin ter poganjkov drugih rastlinskih vrst (Levizou in sod., 2004; Omezzine in sod., 2011; Dor in Hershenhorn, 2012; Andolfi in sod., 2013; Grašič in sod., 2016; Tucker Sernik, 2016). Koncentracija izločkov iz listov ditrihovk se poveča ob suhih, vročih in sončnih poletjih (Stephanou in Manetas, 1995). Jesenska deževja te snovi sperejo $\mathrm{v}$ tla ravno $\mathrm{v}$ času kalitev večine sredozemskih vrst in tako ditrihovkam omogočijo kompeticijsko prednost pred drugimi vrstami (Levizou in sod., 2004; Grašič in sod., 2016).

Stamatakis in Konstantopoulou (2001) sta preučevala vpliv listnega izvlečka lepljive ditrihovke na $\mathrm{N}_{2}$ fiksirajoče cianobakterije. Ugotovila sta, da se $\mathrm{z}$ večanjem koncentracije listnega izvlečka lepljive ditrihovke zmanjša delitev celic cianobakterij. Omezzine in sod. (2011) so ugotovili, da poleg listov, alelopatski potencial kažejo tudi drugi rastlinski organi lepljive ditrihovke. Najboljši alelopatski učinek kažejo izvlečki, pripravljeni iz listov. Znatno manjši učinek kaže izvleček pridobljen iz stebla, najšibkejši učinek pa imajo izvlečki iz korenin. Dor in Hershenhorn (2012) navajata, da so pleveli bolj občutljivi na izvlečke lepljive ditrihovke kot gojene rastline. Andolfi in sod. (2013) so iz desetih izbranih sredozemskih vrst skušali pridobiti izvleček, ki bi najbolj učinkovito zaviral kalitev pojalnikov (Orobanche spp.) in predenic (Cuscuta spp.). Gre za parazitske plevelne vrste, ki lahko vplivajo na manjši pridelek nekaterih gospodarsko pomembnih gojenih vrst rastlin (Parker, 2009). Največji herbicidni potencial je pokazal izvleček nadzemskih delov lepljive ditrihovke (Andolfi in sod., 2013). Rezultati njihove raziskave so pokazali, da so nekatere izolirane učinkovine iz omenjenega izvlečka $\mathrm{v}$ celoti zavrle kalitev testnih rastlinskih vrst. Listni izvleček lepljive ditrihovke bi lahko uporabljali kot selektivni herbicid za bolj trajnostno zatiranje plevelov (Stavrianakou in sod., 2004; Dor in Hershenhorn, 2012; Andolfi in sod., 2013). Slovenski raziskovalci so preučevali kalivost smrdljive in lepljive ditrihovke $\mathrm{v}$ odvisnosti od slanosti podlage (Grašič in sod., 2016a) ter učinek njunih izvlečkov na kalitev izbranih rastlinskih vrst (pelinolistna ambrozija (žvrklja), pšenica in solata) (Grašič in sod., 2016b). Ugotovili so, da obe vrsti ditrihovk uspevata pri vseh koncentracijah soli, a najbolje pri najmanjših. Kalivosti in razvitost kalic je z večanjem koncentracije $\mathrm{NaCl}$ upadala. Vrsti za uspevanje očitno ne zahtevata slane podlage, sta pa zelo tolerantni glede količine soli $\mathrm{v}$ tleh. Avtorji zaključujejo, da je najverjetnejši razlog za njun vzorec širjenja (predvsem ob avtocestah) njuna nezahtevnost ter zmožnost uspevanja na rastiščih z dokaj neugodnimi razmerami, kjer konkurence ni veliko. $\mathrm{V}$ poskusu, kjer so slovenski raziskovalci preučevali učinek izvlečkov lepljive in smrdljive ditrihovke na kalitev izbranih rastlinskih vrst, so rezultati pokazali, da vodna izvlečka obeh vrst ditrihovk zavirata kalitev in nadaljnji razvoj 
testnih vrst, predvsem pelinolistne žvrklje (Grašič in sod., 2016b). Znanstveniki poročajo tudi o akaricidnem delovanju izvlečkov lepljive ditrihovke. Sofou in sod. (2017) so iz rastlinskega izvlečka lepljive ditrihovke izolirali beta-selinensko kislino in preučevali njeno akaricidno delovanje na parazitsko pršico (Varroa destructor [Anderson \& Trueman]) čebel. Laboratorijska raziskava je pokazala, da ima betaselinenska kislina potencialno akaricidno delovanje. Prav tako so raziskovalci tudi potrdili, da omenjena kislina nima neciljnega delovanja na druge organizme.

\subsection{Rastlinske vrste iz rodu Solidago}

Najpomembnejše biološko aktivne snovi, ki jih najdemo $\mathrm{v}$ rastlinah iz zlate rozge so flavonoidi, saponini in terpeni (Apáti, 2003; Starks in sod., 2010). Nekateri terpeni služijo kot zaščita pred žuželkami, herbivori in patogeni (Anžlovar in Dolenc Koce, 2014). Terpeni in saponini imajo prav tako tudi baktericidno in fungicidno delovanje. Starks in sod. (2010) ter Demir in sod. (2009) poročajo o protibakterijski aktivnosti vrste Solidago virgaurea L. proti bakterijam Staphylococcus aureus Rosenbach 1884, Enterococcus faecalis (Andrewes \& Horder, 1906) Schleifer \& Kilpper-Bälz, 1984), Bacillus cereus Frankland \& Frankland 1887 ter Escherichia coli (Migula 1895) Castellani and Chalmers 1919 . V sorodni raziskavi so protibakterijsko delovanje vrste Solidago microglossa DC. proti bakterijam Staphylococcus epidermalis (Winslow \& Winslow) Evans 1916, Staphylococcus aureus, Escherichia coli in Bacillus subtilis (Ehrenberg) Cohn potrdili Morel in sod. (2006). Protibakterijska aktivnost vrste Solidago canadensis je bila potrjena proti bakterijam Escherichia coli, Pseudomonas aureginosa (Schröter) Migula ter Bacillus subtilis Ehrenberg 1835) Cohn 1872 (Mishra in sod., 2010). Zhang in sod. (2009) so potrdili delovanje ekstraktov vrste Solidago canadensis proti glivam Rhizoctonia solani J.G. Kühn, Botrytis cinerea Pers., Alternaria solani (Ellis \& G. Martin) L.R. Jones \& Grout, Colletotrichum lindemuthianum (Sacc. \& Magnus) Briosi \& Cavara, Pythium ultimum Trow ter Rhizoctonia solani. Ugotovljeno je tudi bilo, da rastlinski ekstrakti vrste Solidago canadensis inhibirajo kalitev semen različnih rastlinskih vrst (Butcko in Jensen, 2002; Bing Yao in sod., 2006; Fang in sod., 2007; Abhilasha in sod., 2008; Wang in sod., 2016). Alelopatsko delovanje vrste Solidago canadensis so potrdili Zhang in sod. (2011). Ugotovili so, da se flavoni, saponini in fenoli, ki jih rastlina izloča, akumulirajo $\mathrm{v}$ tleh. Te snovi nato alelopatsko delujejo na talne mikrobe. Zhang in sod. (2009) poročajo, da se vrste iz rodu Solidago v novih habitatih uspešno širijo zaradi alelopatskih snovi, ki jih izločajo in z njimi zavirajo rast okoliških rastlin. $\mathrm{V}$ sorodni raziskavi so Sekutowski in sod. (2012) preučevali vpliv vodnih ekstraktov orjaške zlate rozge (Solidago gigantea) na kalivost semen ajde in sončnice. Pri $50 \%$ koncentraciji vodnega ekstrakta (500 g svežega zelinja je bilo namočenega $v 100 \mathrm{~cm}^{3}$ vode) je bila kalivost semen ajde najmanjša. Najmanjša kalivost semen sončnice je bila ugotovljena pri 12,5 \% koncentraciji vodnega izvlečka orjaške zlate rozge. Baličević in sod. (2015) poročajo o alelopatskem delovanju vodnih ekstraktov orjaške zlate rozge na kalitev semen korenja, ječmena, koriandra in plevelov, navadnega ščira (Amaranthus retroflexus L.) ter baržunastega osleza (Abutilon theophrasti Med.). Ugotovili so inhibiranje kalitve semen pri manjših koncentracijah vodnega ektrakta $(1,5$ in $10 \%)$. Stephan in sod. (2005) poročajo o zmanjšanju okužb listov krompirja, ki so bili tretirani $\mathrm{z}$ vodnim ekstraktom kanadske zlate rozga, $\mathrm{s}$ krompirjevo plesnijo (Phytophthora infestans [Mont.] de Bary). Avtorji zaključujejo, da je bilo delovanje vodnega ekstrakta kanadske rozge sicer manj učinkovito kot uporaba fungicidov na podlagi bakra. Vodni ekstrakt rozge Solidago altissima L. var. scabra ima tudi nematicidno delovanje (Cox in sod., 2006). Avtorji navajajo $40 \%$ smrtnost ogorčic vrste Belonolaimus longicaudatus Rau (1958) v poskusu, ki je potekal v rastlinjaku. Prathibha in sod. (2014) so preučevali larvicidno in ovicidno učinkovitost etilno-acetatnega ekstrakta kanadske zlate rozge pri zatiranju treh vrst komarjev. Sočasno so ugotavljali tudi učinkovitost ekstraktov kot odvračal za odlaganje komarjevih jajčec. V raziskavi so potrdili, da ima ekstrakt kanadske zlate rozge velik potencial pri omejevanju širjenja komarjev.

\subsection{Rastlinske vrste iz rodu Rhus}

Klingauf in sod. (1988) so preučevali insekticidno delovanje etanolnega izvlečka, pripravljenega iz listov navadnega octovca. Etanolni izvleček so preizkušali proti različnim škodljivim žuželčjim vrstam; sivi breskovi uši (Myzus persicae [Sulz.]), svetli žitni uši (Metopolophium dirhodum [Walk.]), črni fižolovi uši (Aphis fabae Scop.), kapusovemu molju (Plutella xylostella [L.]) in hrenarju (Phaedon cochleariae [F.]). Raziskovalci poročajo o visoki smrtnosti listnih uši (med 62 in $76 \%$ ), medtem ko izvleček ni vplival na smrtnost preostalih dveh žuželčjih vrst. S kemično analizo so identificirali prek 70 hlapljivih organskih snovi iz listov navadnega octovca. Kot močno repelentna (odvračalna) snov se je izkazal heksa-hidrofarnesil-aceton (Klingauf in sod., 1988). V sorodni raziskavi Mosch in sod. (1989) so preučevali antibakterijsko učinkovitost 131 različnih rastlinskih izvlečkov proti hruševemu ožigu (Erwinia amylovora [Burrill] Winslow et al.). Izmed učinkovitih se je izkazal prav rastlinski izvleček navadnega octovca, ki je v laboratorijskih testih pokazal zadovoljivo antibakterijsko delovanje proti omenjeni bakteriji. Rayne in Mazza (2007) poročata o antiglivnem delovanju izvlečkov rastlin iz rodu Rhus proti vrstam 
Aspergillus flavus Link, Candida albicans (C.P.Robin) Berkhout, Fusarium tricinctum (Corda) Sacc., Saccharomyces cerevisiae Meyen ex E.C. Hansen in Trichoderma viridae Pers.

\subsection{Rastlinske vrste iz rodu Amorpha}

Liang in sod. (2015) so preučevali insekticidno delovanje rastlinskih izvlečkov navadne amorfe na ličinke komarja Culex pipiens L. Najboljše delovanje je pokazal etanolni izvleček $\left(\mathrm{LC}_{50}=22.69 \mathrm{mg} / \mathrm{L}\right)$. V nadaljnji kemični analizi so $\mathrm{v}$ izvlečku ugotovili prisotnost snovi amorfigenin (8-hidroksirotenon), ki je pokazal larvicidno delovanje $\left(\mathrm{LC}_{50}=4.69 \mathrm{mg} / \mathrm{L}\right.$; $\mathrm{LC}_{90}=11.27 \mathrm{mg} / \mathrm{L}$ ) na omenjeno vrsto komarja. V sorodni raziskavi sta Gombos in Gasko (1977) preučevala vpliv rastlinskega izvlečka navadne amorfe na različne žuželčje vrste. Njuna raziskava je pokazala, da je rastlinski izvleček vplival na zmanjšano hranjenje (kot antifidant) koloradskega hrošča (Leptinotarsa decemlineata [Say]) in gosenic kapusovega belina (Pieris brassicae [L.]), medtem ko na navadno pršico (Tetranychus urticae) ni imel vpliva. Kutas in Nadasy (2005) rezultatov, ki sta jih ugotovila Gombos in Gasko (1977) nista potrdila, saj rastlinski izvleček navadne amorfe ni vplival na zmanjšano hranjenje ličink koloradskega hrošča. Polyakov in sod. (1977) so preučevali repelentni vpliv rastlinskih izvlečkov 607 rastlinskih vrst na različne vrste pršic (Rhipicephalus bursa Canestrini in Fanzago, Dermacentor pictus Herm., Boophilus calcaratus Lahille in Hyalomma detritum [Schulze]). Rastlinski izvleček navadne amorfe se je izkazal kot zelo odvračalen za različne vrste pršic. Csiszár (2009) so preučevali alelopatski vpliv različnih invazivnih lesnih vrst, ki rastejo na Madžarskem, na razvoj bele gorjušice (Sinapis alba L.). Največji alelopatski učinek je bil ugotovljen prav pri uporabi rastlinskega ekstrakta navadne amorfe ter velikega pajesna (Ailanthus altissima).

\subsection{Rastlinske vrste iz rodu Ailanthus}

Balassi in Meszaros (1999) sta preučevala insekticidno delovanje 3,7\% etanolnega izvlečka velikega pajesna na ličinke koloradskega hrošča. Rastlinski izvleček je bil narejen iz listov, vejic in korenin. Z izvlečki so tretirali liste krompirja. Rastlinski izvleček je pokazal učinkovito delovanje le na prvostopenjske ličinke (L1), medtem ko na starejše razvojne stopnje ni imel vpliva. Za vse razvojne stadije pa so potrdili zmanjšano stopnjo prehranjevanja z listi, ki so bili tretirani z rastlinskim izvlečkom velikega pajesna. Za primerjavo so uporabili tudi vodni izvleček, vendar tukaj niso potrdili nikakršnega insekticidnega/antifidantnega delovanja na ličinke koloradskega hrošča. V sorodni raziskavi so kitajski raziskovalci (Bing in sod., 2004) preučevali vpliv rastlinskih izvlečkov velikega pajesna na azijskega kozlička (Anoplophora glabripennis [Motschulsky]). Pri uporabi vodnega izvlečka niso potrdili nobenih razlik s kontrolnim (netretiranim) obravnavanjem v deležu smrtnosti hrošča in njegovo zmožnostjo prehranjevanja. Pri uporabi eternega izvlečka pa so potrdili zmanjšano stopnjo prehranjevanja. Balkan in sod. (2014) so preučevali vpliv rastlinskih izvlečkov iz listov navadnega oreha (Juglans regia L.) ter navadnega pajesna na razvoj nekaterih vrst gliv iz rodov Aspergillus, Penicillium, Fusarium, Giberella in Cladosporium. Rezultati raziskave so pokazali popolno inhibicijo germinacije glive Cladosporium cladosporioides (Fresen.) G.A. de Vries pri uporabi rastlinskega izvlečka velikega pajesna pri koncentraciji $10 \mathrm{mg} / \mathrm{ml}$. Caboni in sod. (2012) so preučevali nematicidno delovanje snovi, ki so jih pridobili iz metanolnega rastlinskega izvlečka velikega pajesna. Snovi (E,E)-2,4-dekadienal $\left(\mathrm{LC}_{50 / 24 \mathrm{~h}}=11.7 \mathrm{mg} / \mathrm{L}\right)$ in $(\mathrm{E})$ 2-dekanal $\left(\mathrm{LC}_{50 / 24 \mathrm{~h}}=20.43 \mathrm{mg} / \mathrm{L}\right)$ sta pokazali visoko stopnjo nematicidnega delovanja proti ogorčici Meloidogyne javanica (Treub). Alelopatsko delovanje rastlinskih izvlečkov velikega pajesna so potrdili v številnih raziskavah (Heisey, 1990; Moradshahi in sod., 2002; De Feo in sod., 2003). Moradashi in sod. (2002) so potrdili alelopatsko delovanje rastlinskega izvlečka velikega pajesna na vrtno krešo (Lepidium sativum L.), njihove rezultate pa so potrdili tudi De Feo in sod. (2003), ki so poročali o alelopatskem delovanju rastlinskih izvlečkov velikega pajesna na vrtno krešo, redkvico (Raphanus sativus L.) in navadni tolščak (Portulaca oleracea L.).

\section{ZAKLJUČEK}

$\mathrm{V}$ članku predstavljamo uporabno vrednost izbranih invazivnih rastlinskih vrst, ki se pojavljajo pri nas in jih je možno uporabljati $v$ varstvu rastlin pred škodljivimi organizmi. Agresivne tujerodne rastline $\mathrm{s}$ hitrim razširjanjem povzročajo nemalo težav ne le domorodnim vrstam rastlin, ker jih izpodrivajo, temveč tudi ljudem, saj so pogosto vzrok za številne zdravstvene težave, kot so alergije, pripomorejo pa tudi $\mathrm{k}$ večji gospodarski škodi. Zatiranje večine tujerodnih invazivnih rastlinskih vrst je zelo težavno (Shaw in sod., 2009; Laznik in Trdan, 2017). V novem okolju namreč največkrat ni naravnih sovražnikov, ki bi vplivali omejevali rast in razvoj teh rastlin.

Organski rastlinski izvlečki so pridobljeni z ekstrakcijo rastlin. Rastline imajo različne aktivne sestavine, ki jih je mogoče pridobiti z različnimi metodami. Ekstrakcija $\mathrm{z}$ vodno ali oljno maceracijo omogoča pridobitev 
aktivnih sestavin rastlin brez njihovega spreminjanja, to so rastlinski izvlečki.

V Sloveniji je danes pridelava mnogih gojenih rastlin ob zadovoljivi kakovosti mogoča le $\mathrm{z}$ uporabo fitofarmacevtskih sredstev. Trenutni trendi v Sloveniji kažejo na zmanjševanje količine porabljenih fitofarmacevtskih sredstev in potrebo po razvoju, optimizaciji in implementaciji novih, nekemičnih načinov zatiranja škodljivih organizmov. Mednje sodijo tudi rastlinski izvlečki invazivnih tujerodnih rastlinskih vrst, ki imajo sodeč po rezultatih dosedanjih raziskav določen potencial $\mathrm{v}$ okoljsko sprejemljivem varstvu rastlin.

\section{ZAHVALA}

Prispevek je nastal v okviru projekta ApPLAuSE (Alien PLAnt SpEcies) - from harmful to useful with citizens' led activities (od škodljivih do uporabnih tujerodnih rastlin $\mathrm{z}$ aktivnim vključevanjem prebivalcev), ki ga financira (2017-2020) Evropski sklad za regionalni razvoj $\mathrm{v}$ okviru pobude Urban Innovative Actions (UIA).

\section{LITERATURA}

Abhilasha D., Quintana N., Vivanco J., Joshi J. (2008). Do allelopathic compounds in invasive Solidago canadensis s.l. restrain the native European flora? Journal of Ecology, 96, 993-1001. doi:10.1111/j.1365-2745.2008.01413.x

Aguilera A.G., Alpert P., Dukes J.S., Harrington R. (2010). Impacts of the invasive plant Fallopia japonica (Houtt.) on plant communities and ecosystem processes. Biological Invasions, 12, 1243-1252. doi:10.1007/s10530-009-9543-z

Andolfi A., Zermane N., Cimmino A., Avolio F., Boari A., Vurro M., Evidente A. (2013). Inuloxins A-D, phytotoxic bi- and tri-cyclic sesquiterpene lactones produced by Inula viscosa: potential for broomrapes and field dodder management. Phytochemistry, $\quad 86, \quad 112-120$. doi:10.1016/j.phytochem.2012.10.003

Anžlovar S., Dolenc Koce S. (2014). Antimicrobial and antifungal acitivity of aqueous and organic extracts from indigenous and invasive species of goldenrod (Solidago spp.) grown in Slovenia. Phyton, 54, 135147.

Balassi G., Meszaros Z. (1999). Tree of heaven (Ailanthus altissima) extracts against the larvae of Colorado potato beetle (Leptinotarsa decemlineata Say). Novenyvedelem, 35, 311-315.

Baličević R., Ravlić M., Živković T. (2015). Allelopathic effect of invasive species giant goldenrod (Solidago gigantea Ait.) on crops and weeds. Herbologia, 15, 19-29. doi:10.5644/Herb.15.1.03

Balkan B., Balkan S., Aydoğdu H., Özcan Ö. (2014). Antifungal activities of Ailanthus altissima Swingle and Juglans regia L. leaves against some cereal fungi. Journal of Applied Biological Sciences, 8, 76-79.

Bardin M., Fargues J., Nicot P.C. (2008) Compatibility between biopesticides used to control grey mould, powdery mildew and whitefly on tomato. Biological Control, 46, 476-483. doi:10.1016/j.biocontrol.2008.05.012

Bing C., Li Hua S., Xi Zeng X. (2004). Effects of Ailanthus altissima and its extract on feeding and oviposition of Anoplophora glabripennis. Journal of Nanjing Forestry University, 28, 15-18.

Bing Yao S., Jian Zhong T., Zhi Gang W., Fu Gen G., Ming De Z. (2006). Allelopathic effects of extracts from Solidago canadensis L. against seed germination and seedling growth of some plants. Journal of Environmental Sciences, 18, 304-309.

Blackburn T.M., Cassey P., Duncan R.P., Evans K.L., Gaston K.J. (2004). Avian extinction and mammalian introductions on oceanic islands. Science, 305, 1955-1958. doi:10.1126/science. 1101617

Butcko V.M., Jensen R.J. (2002). Evidence of tissuespecific allelopathic activity in Euthamia graminifolia and Solidago canadensis (Asteraceae). The American Midland Naturalist, 184, 253-262. doi:10.1674/00030031(2002)148[0253:EOTSAA]2.0.CO;2

Caboni P., Ntalli N.G., Aissani N., Cavoski I., Angioni A. (2012). Nematicidal activity of (E,E)-2-4decadienal and (E)-2-decanal from ailanthus altissima against Melodoigyne javanica. Journal of Agricultural and food Chemistry, 60, 1146-1151. doi:10.1021/jf2044586 
Uporabnost izbranih invazivnih tujerodnih rastlin pri zatiranju škodljivih organizmov gojenih rastlin

Cox C.J., McCarty L.B., Toler J.E., Lewis S.A., Martin S.B. (2006). Suppressing sting nematodes with Brassica sp., poinsettia, and spotted spurge extracts. Agronomy Journal, 98, 962-967. doi:10.2134/agronj2005.0235

Csiszár Á. (2009). Allelopathic effects of invasive woody plant species in Hungary. Acta Silvatica and Lignaria Hungarica, 5, 9-17.

De Feo V., De Martino L., Quaranta E., Pizza C. (2003). Isolation of phytotoxic compounds from tree-ofheaven (Ailanthus altissima Swingle). Journal of Agricultural and Food Chemistry, 51, 1177-1180. doi:10.1021/jf020686+

Demir H., Acik L., Bali E.B., Koc L.Y., Kaynak G. (2009). Antioxidant and antimicrobial activities of Solidago virgaurea extracts. African Journal of Biotechnology, 8, 274-279.

Dor E., Hershenhorn J. (2012). Allelopathic effects of Inula viscosa leaf extracts on weeds. Allelopathy Journal, 30, 281-290.

Fan P., Hostettmann K., Lou H. (2010). Allelochemicals of the invasive neophyte Polygonum cuspidatum Sieb. \& Zucc. (Polygonaceae). Chemoecology, 20, 223-227. doi:10.1007/s00049-010-0052-4

Fang F., Shui Liang G., Hua H., Ying W. (2007). Effects of maceration extract from Solidago canadensis at the flowering stage on the seed germination and growth of three crops. Bulletin of Botanical Research, 27, 569-573.

Gombos M.A., Gasko K. (1977). Extraction of natural antifeedants from the furits of Amorpha fructicosa L. Acta Phytopathologica Academiae scientarum Hungaricae, 12, 349-357.

Grašič M., Anžlovar S., Krajšek Strgulc S. (2016a). Germination rate of stinkwort (Dittrichia graveolans) and false yellowhead (D. viscosa) in relation to salinity. Acta Biologica Slovenica, 59, 511.

Grašič M., Anžlovar S., Krajšek Strgulc S. (2016b). The impact of aqueous extracts of stinkwort (Dittrichia graveolens) and false yellowhead (D. viscosa) on germination of selected plant species. Phyton, 56, 293-301.

Heisey R.M. (1990). Allelopathic and herbicidal effects of extracts from tree of heaven (Ailanthus altissima). American Journal of Botany, 77, 662670. doi:10.1002/j.1537-2197.1990.tb14451.x

Herger G., Klingauf F. (1990). Control of powdery mildew fungi with extracts of the giant knotweed, Reynoutria sachalinensis Polygonaceae. Mededelingen van de Faculteit
Landbouwwetenschappen, Rijksuniversiteit Gent, 55, 1007-1014.

Herger G., Klingauf F., Mangold D., Pommer E.-H., Scherer M. (1988). Efficacy of extracts of Reynoutria sachalinensis F. Schmidt Nakai Polygonaceae, against fungal diseases, especially powdery mildews. Nachrichtenblatt des Deutschen PflanzenSchutzdienstes, 40, 56-60.

Jogan N., Bačič M., Strgulc Krajšek S. (2012). Tujerodne in invazivne rastline v Sloveniji. CRP Neobiota Slovenije-končno poročilo, 161-182.

Klingauf F., Stein U., Bestmann H.J., Vostrowsky O., Classen B., Kobold U. (1988). Herbal insecticides. 6. Effects of an ethanolic leaf extract of Buck's horn (Rhus typhina L.) on different pest insects. Journal of Applied Entomology, 105, 41-47. doi:10.1111/j.1439-0418.1988.tb00159.x

Konstantinidou-Doltsinis S., Schmitt A. (1998). Impact of treatment with plant extracts from Reynoutria sachalinensis F. Schmidt Nakai on disease severity of powdery mildew and yield in cucumber under Greek conditions. Crop Protection, 17, 649-656. doi:10.1016/S0261-2194(98)00066-0

Konstantinidou-Doltsinis S., Markellou E., Kasselaki A.-M., Fanouraki M.N., Koumaki C.M., Schmitt A., Liopa-Tsakalidis A., Malathrakis N.E. (2006). Efficacy of Milsana ${ }^{\circledR}$, a formulated plant extract from Reynoutria sachalinensis, against powdery mildew of tomato (Leveillula taurica). BioControl, 51, 375-392. doi:10.1007/s10526-005-5247-1

Konstantinidou-Doltsinis S., Markellou E., Kasselaki A.-M., Siranidou E., Kalamarakis A., Tzembelikou K., Schmitt A., Koumakiss C., Malathrakis N.E. (2007). Control of powdery mildew of grape in Greece using SporodexReg. L and MilsanaReg. Journal of Plant Diseases and Protection, 114, 256-262. doi:10.1007/BF03356226

Kutas J., Nádasy M. (2005). Antifeedant effects of several plant extracts on Colorado potato beetle larvae. Acta Phytopathologica et Entomologica Hungarica, 40, doi:10.1556/APhyt.40.2005.3-4.17

Lalancette N., Furman L.A., White J.F. (2013) Management of peach rusty spot epidemics with biorational fungicides. Crop Protection, 43, 7-13. doi:10.1016/j.cropro.2012.08.006

Laznik Ž., Trdan S. (2017). Occurence of the common amber snail Succinea putris (L.) (Gastropoda: Styllomatophora) on japanese knotweed (Fallopia japonica [Houtt.] Ronse Decraene) in Slovenia possible weed biocontrol agent. Sustainable Agriculture Research, 6, 21-25. doi:10.5539/sar.v6n2p21 
Levizou E., Karageorgou P., Petropoulou Y., Grammatikopoulos G., Manetas Y. (2004). Induction of ageotropic response in lettuce radicle growth by epicuticular flavonoid aglycons of Dittrichia viscosa. Biologia Plantarum, 48, 305307. doi:10.1023/B:BIOP.0000033462.71065.93

Liang Y., Li X., Gu Z., Qin P., Ji M. (2015). Toxicity of amorphigenin from the seeds of Amorpha fructicosa against the larvae of Culex pipiens pallens (Diptera: Culicidae). Molecules, 20, 32383254. doi:10.3390/molecules20023238

Mishra D., Joshi S., Bisht G., Pilkhwal S. (2010). Chemical composition and antimicrobial activity of Solidago canadensis L. root essential oil. Journal of Basic and Clinical Pharmacy, 1, 187-190.

Moradshahi A., Yaghmaee P., Ghadiri H. (2002). Allelopathic potential of tree of heaven (Ailanthus altissima Swingle). Iran Agricultural research, 21, 27-38.

Moravcova L., Pysek P., Jarosik V., Zakravsky P. (2011). Potential phytotoxic and shading effects of invasive Fallopia (Polygonaceae) taxa on the germination of dominant native species. NeoBiota, 9, 39-47.

Morel A.F., Dias G.O., Porto C., Simionatto E., Stuker C.Z., Dalcol I.I. (2006). Antimicrobial activity of extractives of Solidago microglossa. Fitoterapia, 77, 453-455. doi:10.1016/j.fitote.2006.05.006

Mosch J., Klingauf F., Zeller W. (1989). On the effect of plant extracts against fireblight (Erwinia amylovora). Acta Horticulturae, 273, 355-361. doi:10.17660/ActaHortic.1990.273.52

Murrell C., Gerber E., Krebs C., Parepa M., Schaffner U., Bossdorf O. (2011). Invasive knotweed affects native plants through allelopathy. American Journal of Botany, 98, 38-43. doi:10.3732/ajb.1000135

Neuhaus W., Pallut W. (1992). Modellversuche zur Bekämpfung des Echten Mehltaus Oidium lycopersicum (Cooke et Massee) der Tomate sowie Einfuss von Pflanzenstaerkungsmitteln. Mitteilungen aus der Biologischen undesanstalt fuer Land- und Fortwirtschaft, 283, 193.

Omezzine F., Ladhari A., Rinez A., Haouala R. (2011). Allelopathic potential of Inula graveolens on crops and weeds. Allelopathy Journal, 28, 63-76.

Parker C. (2009). Observations on the current status of Orobanche and Striga problems worldwide. Pest Management Science, 65, 453-459. doi:10.1002/ps.1713
Pavela R., Vrchtová N., Šerá B. (2008). Growth inhibitory effect of extracts from Reynoutria sp. plants against Spodoptera littoralis larvae. Agrociencia, 42, 573-584.

Polyakov D.K., Khaidarov K.M., Shreter A.I. (1977). The acaricidal and repellent effect of plant sof the natural flora of the USSR and introduced species on ixodid ticks. Rastitel'nye Resursy, 13, 267-275.

Prathibha K.P., Raghavendra B.S., Vijayan V.A. (2014). Larvicidal, ovicidal, and oviposition-deterrent activities of four plant extracts against three mosquito species. Environmental Science and Pollution Research, 21, 6736-6743. doi:10.1007/s11356-014-2591-7

Rayne S., Mazza G. (2007). Biological activities of extracts from sumac (Rhus spp.): a review. Plant Foods for Human Nutrition, 62, 165-175. doi:10.1007/s11130-007-0058-4

Sekutowski T.R., Bortniak M., Domaradzki K. (2012). Assessment of allelopathic potential on invasive plants - goldenrod (Solidago gigantea) on buckwheat (Fagopyrum sagittatum) and sunflower (Helianthus annuus). Journal of Research and Applications in Agricultural Engineering, 57, 8691.

Shaw, R.H., Bryner, S., Tanner, R. (2009). The life history and host range of the Japanese knotweed psyllid, Aphalara itadori Shinji: Potentially the first classical biological weed control agent for the European Union. Biological Control, 49, 105-113. doi:10.1016/j.biocontrol.2009.01.016

Sladonja B., Sušek M., Guillermic J. (2015). Review on Invasive Tree of Heaven (Ailanthus altissima [Mil.] Swingle) Conflicting Values: Assessment of Its Ecosystem Services and Potential Biological Threat. Environmental Management, 56, 10091034. doi:10.1007/s00267-015-0546-5

Sofou K., Isaakidis D., Spyros A., Büttner A., Giannis A., Katerinopoulos H.E. (2017). Use of costic acid, a natural extract from Dittrichia viscosa, for the control of Varroa destructor, a parasite of the European honey bee. Beilstein Journal of Organic Chemistry, 13, 952-959. doi:10.3762/bjoc.13.96

Stamatakis K., Konstantopolou M. (2001). Allelopathy effects of aqueous rinses of Dittrichia viscosa (L.) on the photosynthesis and cell proliferation of $\mathrm{N}_{2}$ fixing soil cyanobacteria. Proceedings of the 12th International congress on Phytosynthesis, 3, 4.

Starks C.M., Williams R.B., Goering M.G., O'NeilJohnson M., Norman V.L., Hu J.F., Garo E., Hough G.W., Rice S.M., Eldrige G.R. (2010). Antibacterial clerodane diterpenes from Goldenrod 
(Solidago virgaurea). Phytochemistry, 71, 104-109. doi:10.1016/j.phytochem.2009.09.032

Stavrianakou S., Liakoura V., Levizou E., Karageorgou P., Delis C., Liakopoulos C., Karabourniotis G., Manetas Y. (2004). Allelopathic effects of watersoluble leaf epicuticular meterial from Dittrichia viscosa in seed germination of crops and weeds. Allelopathy Journal, 14, 35-41.

Stephan D., Schmitt A., Martins Carvalho S., Seddon B., Koch E. (2005). Evaluation of biocontrol preparations and plant extracts for the control of Phytophthora infestans on potato leaves. European Journal of Plant Pathology, 112, 235-246. doi:10.1007/s10658-005-2083-1

Stephanou M., Manetas Y. (1995). Allelopathic and water conserving functions of leaf epicuticular exudates in the Mediterranean shrub Dittrichia viscosa. Australian Journal of Plant Physiology, 22, 755-759. doi:10.1071/PP9950755

Stoll P., Gatzsch K., Rusterholz H., Baur B. (2012). Response of plant and gastropod species to knotweed invasion. Basic and Applied Ecology, 13, 232-240. doi:10.1016/j.baae.2012.03.004

Tomczyk A. (2006). Nutritious attractiveness of cucumber leaves to spider mites after treatment with selected inducers of plant resistance. Progress in Plant Protection, 64, 433-436.
Tucker Serniak L. (2016). Comparison of the allelopathic effects and uptake of Fallopia japonica phytochemicaly by Raphanus sativus. European Weed Research Society, 56, 97-101. doi:10.1111/wre.12199

Vrchotová N., Šerá B. (2008). Allelopathic properties of knotweed rhizome extracts. Plant Soil and Environment, 54, 301-303. doi:10.17221/420-PSE

Wang C., Xiao H., Zhao L., Liu J., Wang L., Zhang F., Shi Y., Du D. (2016). The allelopathic effects of invasive plant Solidago canadensis on seed germination and growth of Lactuca sativa enhanced by different types of acid deposition. Ecotoxicology, 25, 555-562. doi:10.1007/s10646016-1614-1

Zhang S., Jin Y., Tang J., Chen X. (2009). The invasive plant Solidago canadensis L. suppresses local soil pathogens through allelopathy. Applied Soil Ecology, 41, 215-222. doi:10.1016/j.apsoil.2008.11.002

Zhang S., Zhu W.J., Wang B., Tang J.J., Chen X. (2011). Secondary metabolites from invasive Solidago canadensis L. accumulation in soil and contribution to inhibition of soil pathogen Pythium ultimum. Applied Soil Ecology, 48, 280-286. doi:10.1016/j.apsoil.2011.04.011 